\title{
The association of insulin resistance and carotid atherosclerosis with thigh and calf circumference in patients with type 2 diabetes
}

\author{
Jong Suk Park ${ }^{1,2}$, Min Ho Cho' ${ }^{1}$ Chul Woo Ahn ${ }^{1,2^{*}}$, Kyung Rae Kim and Kap Bum Huh ${ }^{3}$
}

\begin{abstract}
Background: The relationship between body composition parameters such as thigh and calf circumference and insulin resistance or atherosclerosis in type 2 diabetes is poorly understood. The aim of this study was to investigate the relationship between insulin resistance, atherosclerosis, and thigh and calf circumference in patients with type 2 diabetes.

Methods: A total of 4,427 subjects with type 2 diabetes were enrolled in this study. Insulin sensitivity was assessed according the rate constant for plasma glucose disappearance (Kitt) determined via the short insulin tolerance test. Biochemical and anthropometric profiles were measured according to a standardized protocol. Visceral fat thickness and carotid intima media thickness (IMT) were measured by ultrasonography.

Results: Insulin sensitivity index (Kitt) was significantly correlated with weight adjusted thigh and calf circumference. Thigh circumference was inversely associated with IMT in men and women and calf circumference was negatively correlated with IMT in women. Multiple stepwise regression analysis revealed that thigh circumference was independently correlated with insulin sensitivity index (Kitt) and IMT. Furthermore, in multivariate logistic regression analysis, thigh circumference was an independent determinant factor for carotid atherosclerosis in patients with type 2 diabetes even after adjusting for other cardiovascular risk factors.

Conclusions: Thigh and calf circumference were correlated with insulin resistance and carotid atherosclerosis, and thigh circumference was independently associated with insulin resistance and carotid atherosclerosis in patients with type 2 diabetes.
\end{abstract}

Keywords: Insulin resistance, Intima media thickness, Thigh circumference, Calf circumference, Type 2 diabetes mellitus

\section{Introduction}

Insulin resistance is associated with increased risk of cardiovascular disease (CVD), hypertension, obesity and dyslipidemia and is related to the development of type 2 diabetes [1]. Obesity, especially abdominal obesity, may play a major role in insulin resistance and various metabolic risk factors [2-6], however, recent studies have suggested that body muscle mass is also related to insulin resistance $[1,7]$. As skeletal muscle is an important site

\footnotetext{
* Correspondence: acw@yuhs.ac

'Division of Endocrinology, Department of Internal Medicine, Yonsei University College of Medicine, Seoul, South Korea

${ }^{2}$ Severance Institute for Vascular and Metabolic Research, Yonsei University College of Medicine, Seoul, South Korea

Full list of author information is available at the end of the article
}

of glucose uptake and deposition [8], loss of muscle mass could influence insulin sensitivity and promote metabolic disorders such as diabetes mellitus [1]. Moreover recently, peripheral adiposity in lower body was found to be associated with insulin resistance and glucose metabolism $[9,10]$. Thigh circumference and calf circumference reflect body muscle mass and peripheral subcutaneous fat $[11,12]$. However, there are few reports on the relationship between insulin resistance and thigh and calf circumference [13].

CVD is one of the most common causes of mortality in patients with type 2 diabetes, and carotid atherosclerosis determined by intima media thickness (IMT) is used to predict CVD and related outcomes [14-19]. The association of carotid IMT with body composition 
parameters and fat distribution has not been fully investigated. Several studies have demonstrated a correlation between carotid IMT and abdominal obesity [20-22], but there are few studies of the relationship between body composition parameters such as thigh and calf circumference and carotid atherosclerosis [23,24]. Therefore, in the present study, we investigated the relationship between insulin resistance, IMT, and thigh and calf circumference in patients with type 2 diabetes.

\section{Methods}

\section{Study population}

From 2002 to 2009, total 9,894 patients with type 2 diabetes participated in the Korean Metabolic Syndrome Research Initiative at Huh's Diabetes Center and Diabetes Clinic of Kangnam Severance Hospital. Diagnosis of type 2 diabetes mellitus was based on a previous history of diabetes mellitus or criteria from the American Diabetes Association's diagnostic guidelines. Subjects who had been measured thigh and calf circumference and assessed for both insulin sensitivity and IMT were included in the study. We excluded subjects with a concurrent acute illness including clinically significant infectious disease and chronic disease such as malnutrition, hepatic disease, renal failure and malignant disease. We also excluded subjects with a history of cardiovascular or cerebrovascular disease. Patients who had received thiazolidinedione and insulin were also excluded, as it has been reported to affect insulin resistance as well as IMT. A total of 4,427 subjects were included in the final analyses. The Institutional Review Board of Yonsei University College of Medicine approved the study protocol, and written informed consent was obtained from all participants.

\section{Anthropometric and biochemical parameters}

Height, weight and waist circumference (WC) were measured, and body mass index (BMI) was calculated by dividing weight $(\mathrm{kg})$ by the square of height $\left(\mathrm{m}^{2}\right)$. WC was measured at the midpoint between the lower border of the rib cage and the iliac crest. Thigh circumference was measured at the midpoint from the inguinal crease to the proximal pole of the patella, and calf circumference was measured at the point of greatest circumference. Visceral fat thickness (VFT) was measured using a high resolution ultrasonographic system with a $3.5-\mathrm{MHz}$ convex probe (OGIQ 7, GE, Milwaukee, WI, USA). VFT was defined as the distance between the anterior wall of the aorta and the internal face of the rectoabdominal muscle perpendicular to the aorta at the point of $1 \mathrm{~cm}$ above the umbilicus [25]. We measured blood pressure (BP) in the right upper arm of patients in a sedentary posture while they were seated after having rested for at least $5 \mathrm{~min}$ using a standard sphygmomanometer or an automatic oscillometric BP recorder.

\section{Biochemical parameters}

Blood samples were taken from all subjects after eight hours of fasting. Samples were immediately centrifuged, and plasma and serum samples were stored at $-70^{\circ} \mathrm{C}$ until analysis. Glucose was measured by a standard glucose oxidase method (747 Automatic Analyzer, Hitachi, Tokyo, Japan). Total cholesterol (TC), high density lipoprotein cholesterol (HDL-C), and triglycerides (TG) were measured enzymatically using a chemical analyzer (Daiichi, Hitachi 747, Japan). Subjects with TG levels more than $400 \mathrm{mg} / \mathrm{dL}$ not included and low density lipoprotein cholesterol (LDL-C) was calculated according to the Friedewald formula. Fasting serum insulin was determined by chemiluminescence (RIA Kit, Daiichi, Japan) and glycosylated hemoglobin was measured by immunoturbidimetry (Cobas Integra 800, Roche, Mannheim, Germany), and insulin resistance was estimated using the Homeostasis Model Assessment of Insulin Resistance (HOMA-IR) index, calculated from the following formula: $H O M A-I R=$ fasting insulin $(\mu U / m L) \times$ fasting plasma glu cose $(\mathrm{mmol} / \mathrm{L}) / 22.5$

\section{Assessment of insulin sensitivity}

To evaluate insulin resistance in all subjects, a short insulin tolerance test was performed and assessed by insulin sensitivity index (Kitt) [26-29]. After $12 \mathrm{~h}$ of fasting, an 18-gauge catheter was inserted into one arm, a threeway was connected, and blood was obtained. In the other arm, an antecubital vein was secured for injecting an insulin and dextrose solution. Insulin that had been diluted 100 times (insulin lispro, $0.1 \mathrm{u} / \mathrm{kg}$ ) was then injected. Blood was obtained through the three-way just prior to injection (at "0 min"), and at 3, 6, 9, 12, and 15 min after the injection, serum glucose was measured, and the Kitt value was obtained using the following formula:

$$
\begin{aligned}
& \text { Kitt(rate cons } \tan t \text { for plasma glu cose disappearance }) \\
& =0.693 / t 1 / 2 * 100(\% / \mathrm{min})
\end{aligned}
$$

\section{Carotid artery intima media thickness (IMT)}

Carotid IMT was evaluated by high-resolution B-mode ultrasonography on a single machine (OGIQ 7, GE, Milwaukee, WI, USA) with a $7.5-\mathrm{MHz}$ linear array transducer. Intima media thickness was the distance between the lumen intima interface and media adventitia interface. Measurements of carotid IMT were conducted at three differential plaque free sites: the site of greatest thickness and $1 \mathrm{~cm}$ upstream and $1 \mathrm{~cm}$ downstream from the site of greatest thickness. The mean of the three measurements of the right and left IMT was defined as 
Table 1 Baseline clinical characteristics of subjects

\begin{tabular}{|c|c|c|}
\hline & Men & Women \\
\hline $\mathrm{N}$ & 2,323 & 2,104 \\
\hline Age (years) & $55.75 \pm 11.63$ & $56.50 \pm 11.67$ \\
\hline Duration of diabetes (years) & $6.67 \pm 6.99$ & $6.54 \pm 6.20$ \\
\hline $\mathrm{SBP}(\mathrm{mmHg})$ & $134.02 \pm 17.03$ & $136.84 \pm 18.87$ \\
\hline $\mathrm{DBP}(\mathrm{mmHg})$ & $87.86 \pm 11.25$ & $85.28 \pm 11.32$ \\
\hline Weight (kg) & $70.89 \pm 10.20$ & $59.34 \pm 9.08$ \\
\hline $\mathrm{BMI}\left(\mathrm{kg} / \mathrm{m}^{2}\right)$ & $24.57 \pm 3.25$ & $24.56 \pm 3.34$ \\
\hline WC (cm) & $86.23 \pm 7.74$ & $79.41 \pm 8.31$ \\
\hline Smoking (n, \%) & $354(15.2 \%)$ & $32(1.5 \%)$ \\
\hline Antihypertensive medication, N (\%) & $720(30.9)$ & $694(32.9)$ \\
\hline Antidyslipidemic medication, N (\%) & $464(19.9)$ & $487(23.1)$ \\
\hline \multicolumn{3}{|l|}{ Antidiabetic medication } \\
\hline Sulfonylureas & $1441(62.0)$ & $1328(63.1)$ \\
\hline Metformin & $973(41.8)$ & $1032(49.0)$ \\
\hline AGls & $246(10.6)$ & $231(10.9)$ \\
\hline $\mathrm{FPG}(\mathrm{mmol} / \mathrm{L})$ & $8.25 \pm 2.69$ & $7.91 \pm 2.69$ \\
\hline $\mathrm{TC}(\mathrm{mmol} / \mathrm{L})$ & $4.99 \pm 1.02$ & $5.27 \pm 1.07$ \\
\hline $\mathrm{TG}(\mathrm{mmol} / \mathrm{L})$ & $1.55(1.00-3.19)$ & $1.38(1.00-2.42)$ \\
\hline $\mathrm{LDL}-\mathrm{C}(\mathrm{mmol} / \mathrm{L})$ & $2.96 \pm 0.88$ & $3.16 \pm 0.96$ \\
\hline $\mathrm{HDL}-\mathrm{C}(\mathrm{mmol} / \mathrm{L})$ & $1.23 \pm 0.30$ & $1.35 \pm 0.34$ \\
\hline Insulin $(\mu \mid \mathrm{U} / \mathrm{mL})$ & $6.9(5.1-9.4)$ & $7.6(5.6-10.2)$ \\
\hline HOMA-IR & $2.79 \pm 1.73$ & $2.94 \pm 1.97$ \\
\hline HbA1c (\%) & $8.37 \pm 2.00$ & $8.32 \pm 1.85$ \\
\hline $\operatorname{VAT}(\mathrm{mm})$ & $48.39 \pm 17.23$ & $39.94 \pm 16.45$ \\
\hline Calf circumference (mm) & $35.96 \pm 3.19$ & $33.22 \pm 2.64$ \\
\hline Thigh circumference (mm) & $45.19 \pm 4.03$ & $43.88 \pm 3.99$ \\
\hline Mean IMT(mm) & $0.83 \pm 0.19$ & $0.80 \pm 0.18$ \\
\hline Kitt (\%/min) & $2.28 \pm 0.96$ & $2.31 \pm 0.94$ \\
\hline
\end{tabular}

Data are mean \pm SD or proportion (\%). Data for TG and insulin were skewed distribution, and were presented as the median (interquartile range). SBP, systolic blood pressure; DBP, diastolic blood pressure; BMI, body mass index; WC, waist circumference; FPG, fasting plasma glucose; TC, total cholesterol; TG, triglyceride; LDL-C, low-density lipoprotein cholesterol; HDL-C, high-density lipoprotein cholesterol; Homeostasis Model Assessment of Insulin Resistance, HOMA-IR; HbA1c, hemoglobin A1c; VAT, visceral adipose thickness; IMT, intima media thickness; Kitt, rate constant for plasma glucose disappearance.

the mean IMT. Carotid atherosclerosis was defined as mean IMT $\geq 1.0 \mathrm{~mm}$, as assessed by B-mode ultrasound [30-33].

\section{Statistical analysis}

Data are expressed as means \pm S.D. Intergroup comparisons were performed using ANOVA. Because of the skewed distribution, insulin and TG values were presented as the median (interquartile range) and were log transformed for analysis. A Pearson's correlation analysis was also performed to evaluate the relationship between insulin resistance, IMT and clinical factors including thigh and calf circumference, where indicated. Stepwise multiple linear regression analysis was performed to analyze independent association of insulin sensitivity index (kitt) and IMT adjusting for confounding factors. We selected all the variables shown to be related to kitt and IMT in simple correlation analysis including age, BMI, blood pressure, lipid, smoking habits, and treatment medications. The odds ratios (ORs) with 95\% confidence intervals (CIs) predicting carotid atherosclerosis by thigh and calf circumference were determined by multivariate logistic regression analyses after controlling for other potential confounders. Statistical analyses were carried out using SPSS for Windows 15.0 (SPSS Inc., Chicago, IL, USA). P-values less than 0.05 were considered statistically significant.

Table 2 Correlation between insulin sensitivity index (Kitt), IMT and other variables

\begin{tabular}{|c|c|c|c|c|}
\hline & \multicolumn{2}{|c|}{$\begin{array}{l}\text { Insulin sensitivity } \\
\text { 1index (Kitt) }\end{array}$} & \multicolumn{2}{|c|}{ IMT } \\
\hline & Men & Women & Men & Women \\
\hline$\overline{\text { Age }}$ & $-0.051^{* *}$ & $-0.139^{* *}$ & $0.410^{* *}$ & $0.369^{* *}$ \\
\hline Duration of diabetes & $-0.064^{* *}$ & $-0.060^{*}$ & $0.212^{* *}$ & $0.147^{* *}$ \\
\hline SBP & $-0.125^{* *}$ & $-0.164^{* *}$ & $0.196^{* *}$ & $0.220^{* *}$ \\
\hline $\mathrm{DBP}$ & $-0.126^{* *}$ & $-0.104^{* *}$ & 0.005 & $0.039^{*}$ \\
\hline Weight & $-0.159^{* *}$ & $-0.192^{* *}$ & $0.064^{* *}$ & $0.044^{*}$ \\
\hline BMI & $-0.196^{* *}$ & $-0.216^{* *}$ & 0.029 & $0.064^{* *}$ \\
\hline WC & $-0.277^{* *}$ & $-0.300^{* *}$ & $0.063^{* *}$ & $0.100^{* *}$ \\
\hline Smoking habits & -0.038 & 0.017 & 0.034 & 0.009 \\
\hline FPG & $-0.351^{* *}$ & $-0.370^{* *}$ & 0.025 & 0.006 \\
\hline TC & $-0.140^{* *}$ & $-0.138^{* *}$ & $0.042^{*}$ & $0.071^{* *}$ \\
\hline $\mathrm{TG}$ & $-0.276^{* *}$ & $-0.294^{* *}$ & $0.041^{*}$ & $0.074^{*}$ \\
\hline LDL-C & $-0.052^{* *}$ & $-0.036^{*}$ & $0.080^{* *}$ & $0.071^{* *}$ \\
\hline $\mathrm{HDL}-\mathrm{C}$ & $0.103^{* *}$ & $0.112^{* *}$ & $-0.024^{*}$ & $-0.037^{*}$ \\
\hline Insulin & $-0.215^{* *}$ & $-0.218^{* *}$ & 0.022 & $0.072^{* *}$ \\
\hline HOMA-IR & $-0.347^{* *}$ & $-0.367^{* *}$ & $0.050^{* *}$ & $0.053^{* *}$ \\
\hline $\mathrm{HbAlc}$ & $-0.286^{* *}$ & $-0.195^{* *}$ & $0.073^{* *}$ & 0.016 \\
\hline VAT & $-0.284^{* *}$ & $-0.313^{* *}$ & $0.057^{* *}$ & $0.102^{* *}$ \\
\hline $\begin{array}{l}\text { Weight adjusted calf } \\
\text { circumference }\end{array}$ & $0.211^{* *}$ & $0.258^{* *}$ & -0.027 & $-0.173^{* *}$ \\
\hline $\begin{array}{l}\text { Weight adjusted thigh } \\
\text { circumference }\end{array}$ & $0.244^{* *}$ & $0.279^{* *}$ & $-0.102^{*}$ & $-0.170^{* *}$ \\
\hline Mean IMT & $-0.062^{* *}$ & $-0.092^{* *}$ & & \\
\hline Kitt & & & $-0.062^{* *}$ & $-0.092^{* *}$ \\
\hline
\end{tabular}

${ }^{*} \mathrm{P}<0.05,{ }^{* * P}<0.01$.

SBP, systolic blood pressure; DBP, diastolic blood pressure; BMI, body mass index; WC, waist circumference; FPG, fasting plasma glucose; TC, total cholesterol; TG, triglyceride; LDL-C, low-density lipoprotein cholesterol; HDL-C, high-density lipoprotein cholesterol; Homeostasis Model Assessment of Insulin Resistance, HOMA-IR; HbA1c, hemoglobin A1c; VAT, visceral adipose thickness; IMT, intima media thickness; Kitt, rate constant for plasma glucose disappearance. 


\section{Results}

The clinical and laboratory characteristics of the study population are summarized in Table 1 . The study included 2,323 men aged $55.75 \pm 11.63$ years and 2,104 women aged $56.50 \pm 11.67$ years. Thigh and calf circumference were adjusted for body weight and height, and since thigh and calf circumference showed a stronger association with body weight (thigh circumference, calf circumference: $r=0.701$, $\mathrm{r}=0.729$ in men, $\mathrm{r}=0.722, \mathrm{r}=0.744$ in women; all $\mathrm{p}<0.01$ ) than body height (thigh circumference, calf circumference: $\mathrm{r}=0.280, \mathrm{r}=0.327$ in men, $\mathrm{r}=0.171, \mathrm{r}=0.368$ in women; all $\mathrm{p}<0.01$ ), they were adjusted by body weight (Additional file 1: Figure S1, S2). The insulin sensitivity index (Kitt) was significantly correlated with weight adjusted thigh and calf circumference in both men and women (Table 2, Figure 1). Figure 2 shows carotid IMT in quartiles of thigh and calf circumference. In both men and women, carotid IMT differed among the four groups of thigh and calf circumference. Thigh circumference was inversely associated with IMT in men and women, and calf circumference was negatively correlated with IMT in women (Table 2).

In stepwise multiple linear regression analysis, WC, FPG, TG, HbA1c, insulin, VAT and thigh circumference were significantly associated with insulin sensitivity index (kitt), but age, blood pressure, calf circumference and smoking habits, and treatment medications were not associated with insulin sensitivity index (kitt) (Table 3). Stepwise multiple linear regression analysis for IMT showed that thigh circumference was independently associated with IMT in addition to age, SBP, duration of diabetes, LDL-C, and VAT. While, calf circumference, smoking habits, and treatment medications were not associated with IMT (Table 4).

According to multivariate logistic regression analysis, the OR of carotid atherosclerosis according to the quartiles of thigh circumference were showed in Table 5 . However, the association of quartiles of calf circumference with carotid atherosclerosis was not significant (data not shown). The OR for carotid atherosclerosis increased according to the decreased thigh circumference based on an unadjusted model. Adjustments for age, duration of diabetes, smoking status, BMI, blood pressure, lipid, kitt, WC, VAT and treatment medications, the association between carotid atherosclerosis and thigh circumference remained significant. The results of regression analysis indicated that thigh circumference was independently correlated with insulin resistance and carotid atherosclerosis.

\section{A}

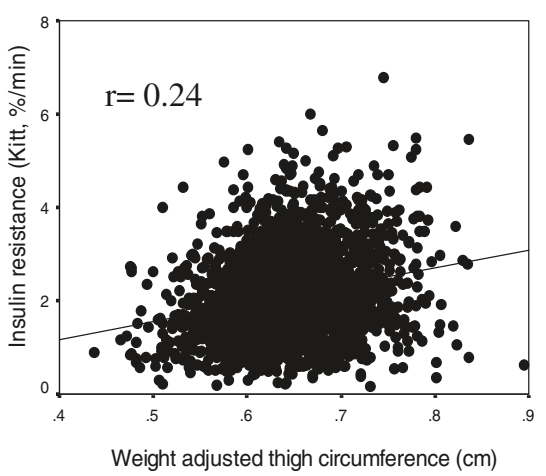

B

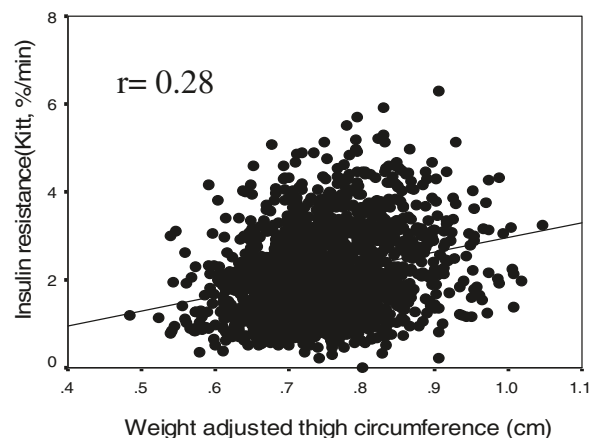

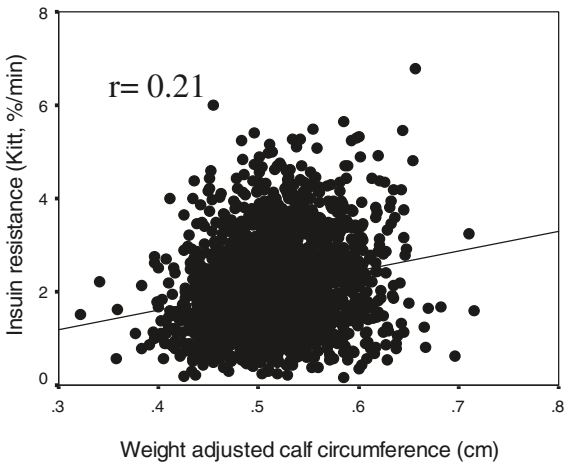

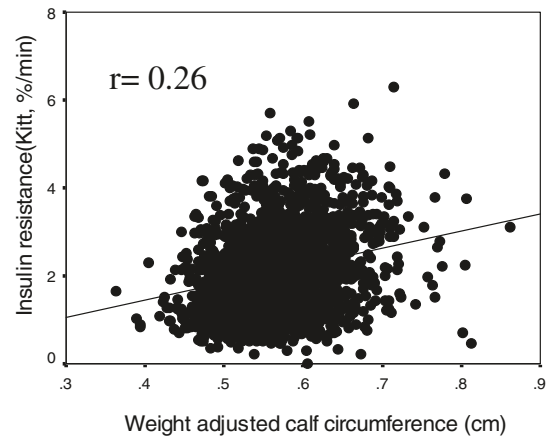

Figure 1 The relationship between insulin resistance and thigh and calf circumference in men (A) and women (B). The insulin sensitivity index (Kitt) was significantly correlated with weight adjusted thigh and calf circumference in both men and women $(P<0.01)$. 

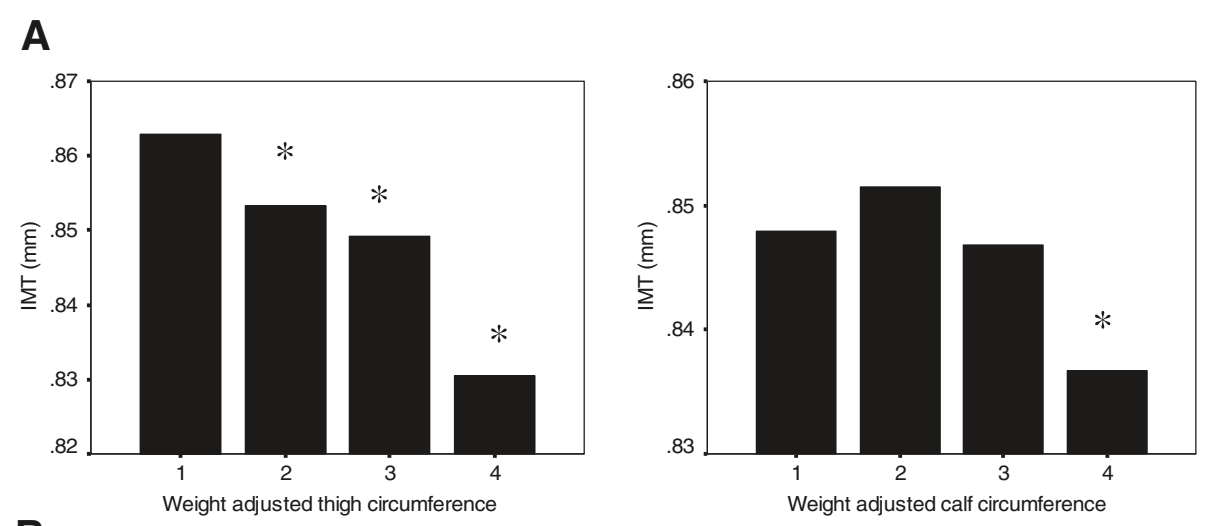

B
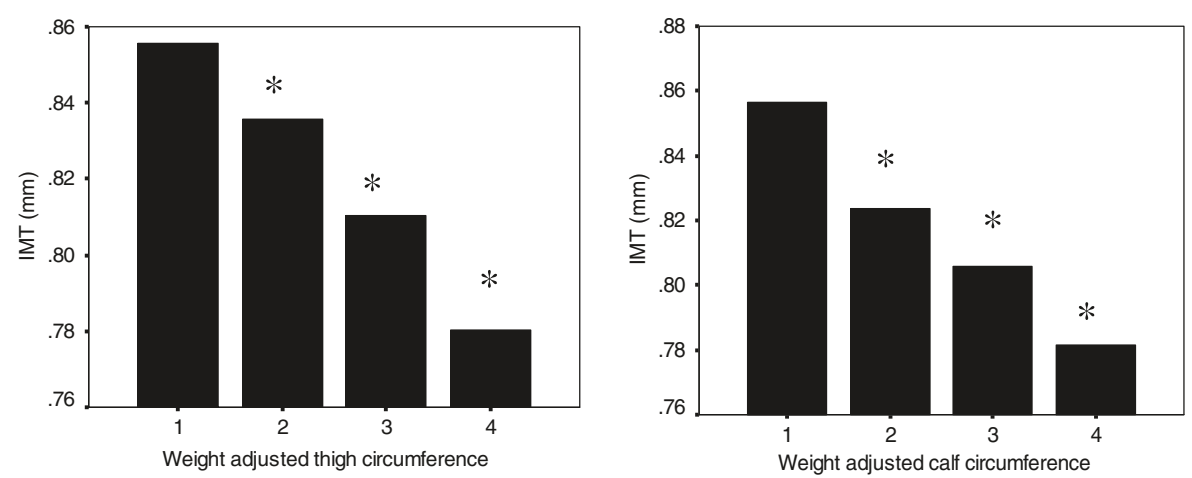

Figure 2 The relationship between intima media thickness and thigh and calf circumference in men (A) and women (B). Carotid IMT differed among the four groups of thigh and calf circumference $(P<0.05$ vs. first tertile).

\section{Discussion}

This study found that calf and thigh circumference was significantly correlated with insulin resistance and IMT, and thigh circumference was independently associated with insulin resistance and IMT in patients with type 2 diabetes. Furthermore, thigh circumference was an independent determinant factor for carotid atherosclerosis, even after adjusting for other cardiovascular risk factors.

Table 3 Multiple stepwise regression analysis showing variables independently associated with insulin sensitivity index (Kitt)

\begin{tabular}{lcc}
\hline & Men $\left(\gamma^{2}=\mathbf{0 . 3 3}\right)$ & Women $\left(\gamma^{2}=\mathbf{0 . 2 2}\right)$ \\
\hline WC & $-0.182^{* *}$ & $-0.199^{* *}$ \\
FPG & $-0.286^{* *}$ & $-0.230^{* *}$ \\
TG & $-0.110^{* *}$ & $-0.139^{* *}$ \\
Insulin & $-0.178^{* *}$ & $-0.172^{* *}$ \\
HbA1C & $-0.123^{* *}$ & $-0.156^{* *}$ \\
VAT & $-0.136^{* *}$ & $-0.145^{* *}$ \\
Weight adjusted thigh & $0.128^{* *}$ & $0.141^{* *}$ \\
circumference & &
\end{tabular}

* $P<0.05,{ }^{* *} \mathrm{P}<0.01$.

WC, waist circumference; FPG, fasting plasma glucose; TG, triglyceride; HbA1C, hemoglobin A1c;VAT, visceral adipose thickness; Kitt, rate constant for plasma glucose disappearance.
There is growing evidence that peripheral adipocity and muscle mass are of major importance in determining insulin resistance $[1,7,9,10]$. Computed tomography $(\mathrm{CT})$ is an accurate method for measuring body composition parameters including leg muscle mass and magnetic resonance spectroscopy is a powerful method for assessing lipid content in muscle [34-37]. However, the cost of CT or magnetic resonance spectroscopy is high, therefore CT and magnetic resonance spectroscopy are not suitable as a screening test. In contrast, thigh and calf circumferences

Table 4 Multiple stepwise regression analysis showing variables independently associated with IMT

\begin{tabular}{lcc}
\hline & Men $\left(\boldsymbol{\gamma}^{\mathbf{2}}=\mathbf{0 . 1 8}\right)$ & Women $\left(\boldsymbol{\gamma}^{\mathbf{2}=\mathbf{0 . 2 3})}\right.$ \\
\hline Age & $0.351^{* *}$ & $0.347^{* *}$ \\
SBP & $0.143^{* *}$ & $0.151^{* *}$ \\
Duration of diabetes & $0.094^{* *}$ & $0.067^{* *}$ \\
LDL-C & $0.108^{* *}$ & $0.085^{* *}$ \\
VAT & $0.073^{* *}$ & $0.103^{* *}$ \\
Weight adjusted thigh & $-0.092^{*}$ & $-0.124^{* *}$ \\
circumference & &
\end{tabular}

* $P<0.05,{ }^{*} \mathrm{P}<0.01$.

SBP, systolic blood pressure; LDL-C, low-density lipoprotein cholesterol; VAT, visceral adipose thickness; IMT, intima media thickness. 


\section{Table 5 The Odds ratios $(95 \% \mathrm{Cl})$ for carotid atherosclerosis according to thigh circumference quartiles}

\begin{tabular}{|c|c|c|c|}
\hline & & OR $(95 \% \mathrm{Cl})$ & Adjusted $\mathrm{OR}^{\mathrm{a}}(95 \% \mathrm{Cl})$ \\
\hline \multirow[t]{4}{*}{ Men } & Quartile 1 & $1.59^{*}(1.00-2.35)$ & $1.46^{*}(0.98-2.27)$ \\
\hline & Quartile 2 & $1.36^{*}(0.98-1.91)$ & $1.35^{*}(0.99-1.93)$ \\
\hline & Quartile 3 & $1.33^{*}(0.95-1.88)$ & $1.30^{*}(0.93-1.64)$ \\
\hline & Quartile 4 & 1 & 1 \\
\hline \multirow[t]{4}{*}{ Women } & Quartile 1 & $2.37^{* *}(1.57-3.55)$ & $1.86^{* *}(1.16-3.05)$ \\
\hline & Quartile 2 & $1.79^{* *}(1.17-2.73)$ & $1.55^{* *}(0.95-2.32)$ \\
\hline & Quartile 3 & $1.41^{*}(0.98-2.13)$ & $1.33^{*}(0.82-1.89)$ \\
\hline & Quartile 4 & 1 & 1 \\
\hline
\end{tabular}

* $P<0.05$, ** $P<0.01$.

${ }^{a}$ Adjusted for age, duration of diabetes, smoking status, BMI, blood pressure, lipid, kitt, WC, VAT and treatment medications.

are crude indices of muscle mass and peripheral subcutaneous fat as compared with $\mathrm{CT}$ and magnetic resonance spectroscopy, because thigh circumference and calf circumference reflect body muscle mass and peripheral subcutaneous fat $[11,12]$, these measurements are noninvasive and easily applicable and they are more suitable as screening tools.

This study of 4,427 patients measured thigh and calf circumference and insulin resistance and demonstrated that insulin resistance was significantly correlated with thigh and calf circumference in patients with type 2 diabetes. The correlations were stronger with thigh circumference than calf circumference. Additionally, we found that thigh circumference was an important independent factor associated with insulin resistance in patients with type 2 diabetes. M. Ochi et al. recently reported that thigh muscle area did not appear to be significantly correlated with insulin resistance in elderly Japanese men [34]. In another study by Lee et al., thigh circumference was significantly associated with insulin resistance in peri- and postmenopausal women [13]. Taken together, these results suggest that thigh circumference, may be useful indicators of insulin resistance in Korean patients with type 2 diabetes.

Few studies have evaluated the relationship between body composition parameters such as thigh and calf circumference and atherosclerosis. Calf circumference is associated with carotid plaques in elderly subjects [23], thigh muscle area is related to ankle brachial pressure index (ABI) in elderly men [34], and reduced thigh muscle mass area is independently related to IMT in hemodialysis patients [24]. Recent studies reported that peripheral adiposity is associated with several markers of atherosclerosis such as aortic calcification, coronary angiography score, and arterial stiffness [38-40]. In the present study, calf circumference was correlated with
IMT in women but not in men, and the association between calf circumference and IMT in women disappeared after regression analysis. But we found that decreased thigh circumference quartiles were also associated with increasing IMT in men and women, and thigh circumference was independently associated with IMT and carotid atherosclerosis. The increased odds ratio for carotid atherosclerosis was independent of general and abdominal obesity and cardiovascular risk factors, such as blood pressure and lipid. This results of the present study corroborate previous findings that low thigh circumference is associated with an increased risk of developing heart disease and premature death [12]. Although the mechanism underlying the relationship of thigh circumference and atherosclerosis is unknown, it was explained that less muscle mass and increased peripheral subcutaneous fat are associated with atherosclerotic markers [37-40].

Several limitations of our study need to be considered. First, based on its cross-sectional study design, the present findings are inherently limited in the ability to eliminate causal relationships between thigh and calf circumference and carotid IMT. Since some of the study population had several risk factors including hypertension, and dyslipidemia, the authors could not eliminate the possible effect of underlying diseases and medications used for these diseases on the present findings. Further prospective population-based studies are needed to investigate the mechanisms in order to answer these questions. Second, we did not measure thigh muscle area and did not consider muscle quality, such as muscle strength. Muscle strength has been shown to be more relevant to functional alteration than muscle mass in several studies [41]. Third, more detailed characteristics such as muscular lipid content assessed by $\mathrm{CT}$, biopsy or magnetic resonance spectroscopy were not measured in this study. Kim et al. reported that altered lipid partitioning in skeletal muscle might be important in the development of insulin resistance and atherosclerosis [42]. Further studies employing imaging devices such as CT and MRI to measure calf and thigh muscle and lipid content could improve our understanding of the roles played by calf and thigh muscle in association with IMT as well as assess any differences by gender.

\section{Conclusions}

In conclusion, calf and thigh circumference were correlated with insulin resistance and IMT, and thigh circumference was independently associated with insulin resistance and IMT in patients with type 2 diabetes. These results suggest that thigh circumference may be a new anthropometric marker of insulin resistance and carotid atherosclerosis. 


\section{Additional file}

Additional file 1: Figure S1. The relationship between height, body weight, and thigh and calf circumference in men; $P<0.01$. Figure S2 The relationship between height, body weight, and thigh and calf circumference in women; $P<0.01$.

\section{Abbreviations}

SBP: Systolic blood pressure; DBP: Diastolic blood pressure; BMI: Body mass index; WC: Waist circumference; FPG: Fasting plasma glucose; TC: Total cholesterol; TG: Triglyceride; LDL-C: Low-density lipoprotein cholesterol; HDL-C: High-density lipoprotein cholesterol; HbA1c: Hemoglobin A1c; VAT: Visceral adipose thickness; IMT: Intima media thickness.

\section{Competing interests}

The authors declare that they have no competing interests.

\section{Acknowledgements}

This study was supported by a grant from the Seoul R\&BD Program, Republic of Korea (10526)

\section{Author details}

${ }^{1}$ Division of Endocrinology, Department of Internal Medicine, Yonsei University College of Medicine, Seoul, South Korea. ${ }^{2}$ Severance Institute for Vascular and Metabolic Research, Yonsei University College of Medicine, Seoul, South Korea. ${ }^{3}$ Huh's Diabetes Center and the 21st Century Diabetes and Vascular Research Institute, Seoul, South Korea.

\section{Authors' contributions}

Study design, data analysis and manuscript writing: JSP; data collection and analysis: MHC; study design and conduct: CWA; Manuscript revision: KRK, $\mathrm{KBH}$. All authors read and approved the manuscript.

Received: 28 March 2012 Accepted: 8 June 2012

Published: 8 June 2012

\section{References}

1. Reaven GM: Role of insulin resistance in human disease. Diabetes 1988 37:1595-1607.

2. Ziaei S, Sayahi M, Faghihzadeh S: Relationship between reproductive aging, body composition, hormonal status and metabolic syndrome in postmenopausal women. Climacteric 2011, 14:649-653.

3. Koh H, Hayashi T, Sato KK, Harita N, Maeda I, Nishizawa Y, Endo G, Fujimoto WY, Boyko EJ, Hikita Y: Visceral adiposity, not abdominal subcutaneous fat area, is associated with high blood pressure in Japanese men: the Ohtori study. Hypertens Res 2011, 34:565-572.

4. Bozorgmanesh M, Hadaegh F, Khalili D, Azizi F: Prognostic significance of the Complex "Visceral Adiposity Index" vs. simple anthropometric measures: Tehran Lipid and Glucose Study. Cardiovasc Diabeto/ 2012, 11:20 [Epub ahead of print].

5. Mirrakhimov AE, Lunegova OS, Kerimkulova AS, Moldokeeva CB, Nabiev MP, Mirrakhimov EM: Cut off values for abdominal obesity as a criterion of metabolic syndrome in an ethnic Kyrgyz population (central Asian region). Cardiovasc Diabetol 2012, 11:16 [Epub ahead of print].

6. Hayashi T, Boyko EJ, McNeely MJ, Leonetti DL, Kahn SE, Fujimoto WY: Visceral adiposity, not abdominal subcutaneous fat area, is associated with an increase in future insulin resistance in Japanese Americans. Diabetes 2008, 57:1269-1275.

7. Huh KB: Clinical and biochemical characteristics of Korean patients with non insulin-dependent diabetes mellitus. In Proceedings of the 8th Japan Korea Symposium on Diabetes Mellitus: 27-30 Oct 1995; Ube, Japan. Edited by Japan Diabetes Society, : Japan Diabetes Society and Korean Diabetes Association; 1995:34-35.

8. Klip A, Paquet MR: Glucose transport and glucose transporters in muscle and their metabolic regulation. Diabetes Care 1990, 13:228-243.

9. Van Pelt RE, Evans EM, Schechtman KB, Ehsani AA, Kohrt WM: Contributions of total and regional fat mass to risk for cardiovascular disease in older women. Am J Physiol Endocrinol Metab 2002, 282:1023-1028.

10. Snijder MB, Visser M, Dekker JM, Goodpaster BH, Harris TB, Kritchevsky SB, De Rekeneire N, Kanaya AM, Newman AB, Tylavsky FA, Seidell JC: Low subcutaneous thigh fat is a risk factor for unfavourable glucose and lipid levels, independently of high abdominal fat. The health $A B C$ study. Diabetologia 2005, 48:301-308.

11. Kwon HR, Han KA, Ahn HJ, Lee JH, Park GS, Min KW: The Correlations between Extremity Circumferences with Total and Regional Amounts of Skeletal Muscle and Muscle Strength in Obese Women with Type 2 Diabetes. Diabetes Metab J 2011, 35:374-383.

12. Heitmann $B L$, Frederiksen P: Thigh circumference and risk of heart disease and premature death: prospective cohort study. BMJ 2009, 339:729-735.

13. Lee JK, Wu CK, Lin LY, Cheng CL, Lin JW, Hwang JJ, Chiang FT: Insulin resistance in the middle-aged women with Tigerish Back and Bearish Waist. Diabetes Res Clin Pract 2010, 90:85-87.

14. Tang R, Hennig M, Thomasson B, Scherz R, Ravinetto R, Catalini R, Rubba $P$ Zanchetti A, Bond MG: Baseline reproducibility of B-mode ultrasound imaging measurements of carotid intima media thickness. J Hypertens 2000, 18:197-201.

15. Din-Dzietham R, Liao D, Diez-Roux A, Nieto FJ, Paton C, Howard G, Brown A, Carnethon M, Tyroler HA: Association of coronary heart disease incidence with carotid arterial wall thickness and major risk factors; the ARIC study, 1987-1993. Am J Epidemiol 1997, 146:483-494.

16. Hodis HN, Mack WJ, LaBree L, Selzer RH, Liu CR, Liu CH, Azen SP: The role of carotid arterial intima-media thickness in predicting clinical coronary events. Ann Intern Med 1998, 128:262-269.

17. O'Leary DH, Polak JF, Kronmal RA, Manolio TA, Burke GL, Wolfson SK: Cardiovascular health study collaborative research group: Carotid artery intima and media thickness as a risk factor for myocardial infarction and stroke in older adults. New Engl J Med 1999, 340:14-22.

18. Gomez-Marcos MA, Recio-Rodríguez JI, Patino-Alonso MC, Agudo-Conde C, Gomez-Sanchez L, Rodriguez-Sanchez E, Gomez-Sanchez M, Garcia-Ortiz L: Yearly evolution of organ damage markers in diabetes or metabolic syndrome: data from the LOD-DIABETES study. Cardiovasc Diabetol 2011 10:90

19. Lundby-Christensen L, Almdal TP, Carstensen B, Tarnow L, Wiinberg N: Carotid intima-media thickness in individuals with and without type 2 diabetes: a reproducibility study. Cardiovasc Diabetol 2010, 9:40.

20. Reed D, Dwyer KM, Dwyer JH: Abdominal obesity and carotid artery wall thickness. The Los Angeles Atherosclerosis Study. Int J Obes Relat Metab Disord 2003, 27:1546-1551.

21. Yamamoto $M$, Egusa $G$, Hara $H$, Yamakido M: Association of intra abdominal fat and carotid atherosclerosis in non-obese middle-aged men with normal glucose tolerance. Int J Obes Relat Metab Disord 1997 21:948-951

22. Park JS, Ahn SG, Hwang JW, Lim HS, Choi BJ, Choi SY, Yoon MH, Hwang GS, Tahk SJ, Shin JH: Impact of body mass index on the relationship of epicardial adipose tissue to metabolic syndrome and coronary artery disease in an Asian population. Cardiovasc Diabetol 2010, 9:29.

23. Debette S, Leone N, Courbon D, Gariépy J, Tzourio C, Dartigues JF, Ritchie K, Alpérovitch A, Ducimetière $P$, Amouyel $P$, Zureik M: Calf circumference is inversely associated with carotid plaques. Stroke 2008, 39:2958-2965.

24. Kato A, Ishida J, Endo Y, Takita T, Furuhashi M, Maruyama Y, Odamaki M: Association of abdominal visceral adiposity and thigh sarcopenia with changes of arteriosclerosis in haemodialysis patients. Nephrol Dial Transplant 2011, 26:1967-1976.

25. Kim SK, Kim HJ, Hur KY, Choi SH, Ahn CW, Lim SK, Kim KR, Lee HC, Huh KB, Cha BS: Visceral fat thickness measured by ultrasonography can estimate not only visceral obesity but also risks of cardiovascular and metabolic diseases. Am J Clin Nutr 2004, 79:593-599.

26. Bonora E, Moghetti P, Zancanaro C, Cigolini M, Querena M, Cacciatori V, Corgnati A, Muggeo M: Estimates of in vivo insulin action in man: comparison of insulin tolerance tests with euglycemic and hyperglycemic glucose clamp studies. J Clin Endocrinol Metab 1989, 68:374-378.

27. Young RP, Critchley JA, Anderson PJ, Lau MS, Lee KK, Chan JC: The short insulin tolerance test: feasibility study using venous sampling. Diabet Med 1996, 13:429-433.

28. Alberti KG, Daly ME, Robinson A, Marshall SM, Mathers JC: The short insulin tolerance test is safe and reproducible. Diabet Med, 16:352-353.

29. Park SW, Yun YS, Ahn CW, Nam JH, Kwon SH, Song MK: Short insulin tolerance test for the determination of in vivo insulin sensitivity: a comparison with euglycemic clamp test. Kor Diabetes J 1998, 22:199-208. 
30. Jackson R, Chambless LE, Yang K, Byrne T, Watson R, Folsom A, Shahar E, Kalsbeek W: Differences between respondents and nonrespondents in a multicenter community-based study vary by gender ethnicity. The Atherosclerosis Risk in Communities (ARIC) Study Investigators. J Clin Epidemiol 1996, 49:1441-1446.

31. Pignoli P, Tremoli E, Poli A, Oreste P, Paoletti R: Intimal plus medial thickness of the arterial wall: a direct measurement with ultrasound imaging. Circulation 1986, 74:1399-1406.

32. O'Leary DH, Polak JF, Kronmal RA, Manolio TA, Burke GL, Wolfson SK Jr: Carotid-artery intima and media thickness as a risk factor for myocardial infarction and stroke in older adults: Cardiovascular Health Study Collaborative Research Group. N Engl J Med 1999, 340:14-22.

33. Chambless LE, Folsom AR, Clegg LX, Sharrett AR, Shahar E, Nieto FJ, Rosamond WD, Evans G: Carotid wall thickness is predictive of incident clinical stroke: the Atherosclerosis Risk in Communities Study. Am J Epidemiol 2000, 151:478-487.

34. Ochi M, Kohara K, Tabara Y, Kido T, Uetani E, Ochi N, Igase M, Miki T: Arterial stiffness is associated with low thigh muscle mass in middleaged to elderly men. Atherosclerosis 2010, 212:327-332.

35. Lim Kl, Yang SJ, Kim TN, Yoo HJ, Kang HJ, Song W, Baik SH, Choi DS, Choi $\mathrm{KM}$ : The association between the ratio of visceral fat to thigh muscle area and metabolic syndrome: the Korean Sarcopenic Obesity Study (KSOS). Clin Endocrinol 2010, 73:588-594.

36. Petersen KF, Dufour S, Befroy D, Garcia R, Shulman G: Impaired mitochondrial activity in the insulin-resistant offspring of patients with type 2 diabetes. N Engl J Med 2004, 350:664-671.

37. Boesch C, Slotboom J, Hoppeler H, Kreis R: In vivo determination of intra myocellular lipids in human muscle by means of localized 1H-MRspectroscopy. Magn Reson Med 1997, 37:484-493.

38. Tanko LB, Bagger YZ, Alexandersen P, Larsen PJ, Christiansen C: Peripheral adiposity exhibits an independent dominant anti atherogenic effect in elderly women. Circulation 2003, 107:1626-1631.

39. Hara M, Saikawa T, Kurokawa M, Sakata T, Yoshimatsu H: Leg fat percentage correlates negatively with coronary atherosclerosis. Circ $J$ 2004, 68:1173-1178.

40. Ferreira I, Snijder MB, Twisk JW, van Mechelen W, Kemper HC, Seidell JC, Stehouwer CD: Central fat mass versus peripheral fat and lean mass: opposite (adverse versus favorable) associations with arterial stiffness? The Amsterdam Growth and Health Longitudinal Study. J Clin Endocrinol Metab 2004, 89:2632-2639.

41. Visser M, Newman AB, Nevitt MC, Kritchevsky SB, Stamm EB, Goodpaster BH, Harris TB: Reexamining the sarcopenia hypothesis. Muscle mass versus muscle strength. Health, Aging, and Body Composition Study Research Group. Ann N Y Acad Sci 2000, 904:456-461.

42. Kim SK, Park SW, Hwang IJ, Lee YK, Cho YW: High fat stores in ectopic compartments in men with newly diagnosed type 2 diabetes: an anthropometric determinant of carotid atherosclerosis and insulin resistance. Int J Obes 2010, 34:105-110.

doi:10.1186/1475-2840-11-62

Cite this article as: Park et al:: The association of insulin resistance and carotid atherosclerosis with thigh and calf circumference in patients with type 2 diabetes. Cardiovascular Diabetology 2012 11:62.

\section{Submit your next manuscript to BioMed Central and take full advantage of:}

- Convenient online submission

- Thorough peer review

- No space constraints or color figure charges

- Immediate publication on acceptance

- Inclusion in PubMed, CAS, Scopus and Google Scholar

- Research which is freely available for redistribution

Submit your manuscript at www.biomedcentral.com/submit
C Biomed Central 